" دراسة تأثير الزيت العطرى لنبات بيوليكاريا أنديولاتا ( الثاى الجبلى ) النامى بصحراء مدينة السادات على بعض الإل

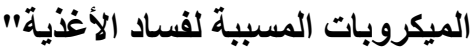

أسماء عبد المقصود السيد الثقبري',محمد فتحي عزازي”, يحيي عبد المنعم عبد الله ا ـ باحثة در اسات عليا بمعهة الدر اسات و البحوث البيئية - جامعة مدينة السادات

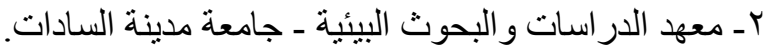

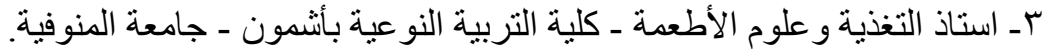

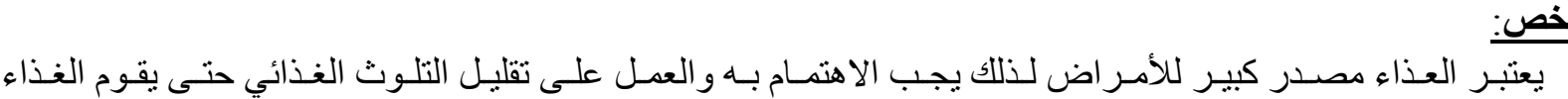

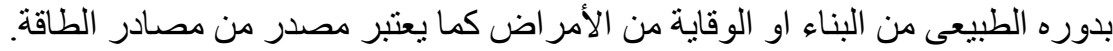

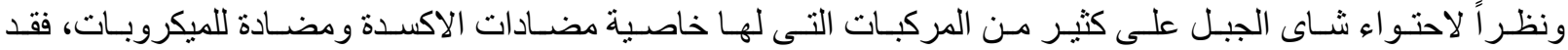

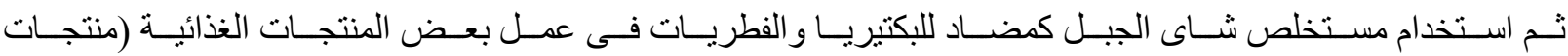

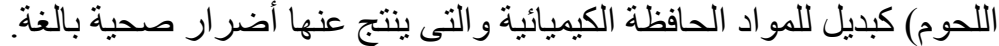

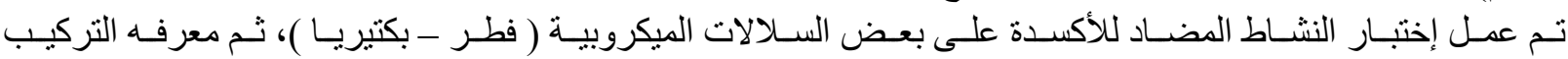

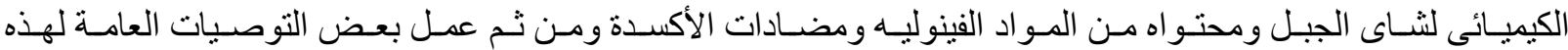

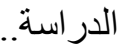

\title{
ABSTRACT
}

The food is considered a big source for food borne diseases, thus we must reduce food contamination to make food a source of energy, and prevent food diseases.

Due to the Pulicaria undulata (Shai Gabaly) contains many antioxidant and antimicrobial compounds, so we used the plant extract as an antibacterial and fungal antiseptic in the production of some food products (meat products) as an alternative to chemical preservatives, resulting in severe health damage.

The antioxidant activity was tested on some microbial strains (Fungus and bacteria), then chemical composition, phenolic and antioxidants substances, and then making general recommendations for this study.

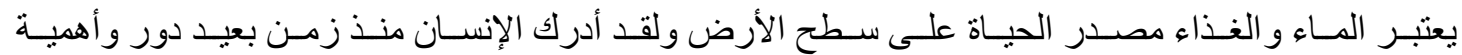

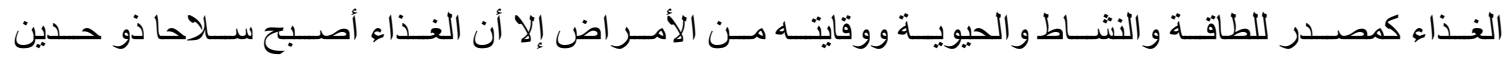

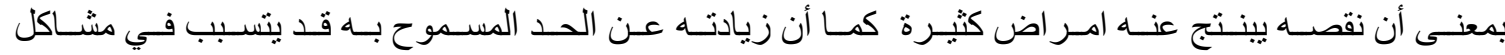

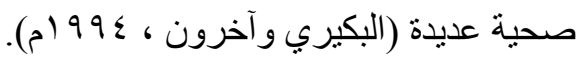

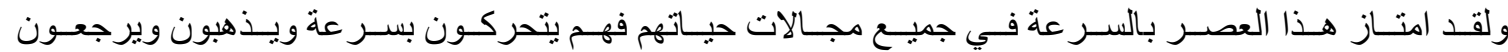

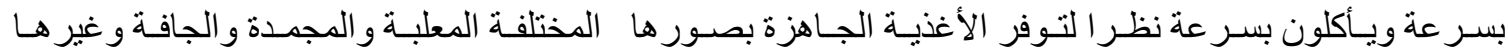

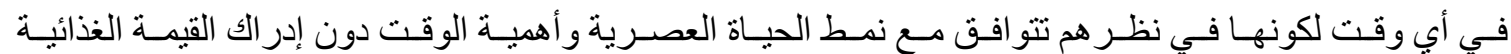
في أولويات إختيار هم لتلك الأغذية. 


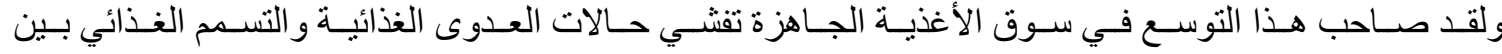

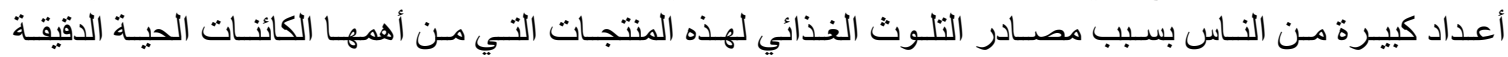

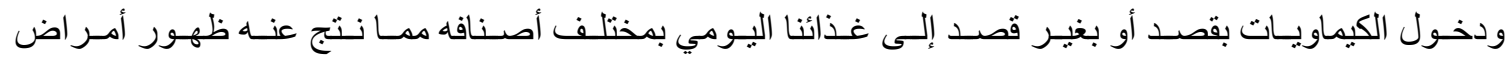

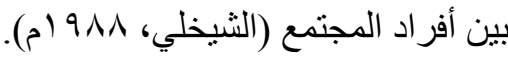

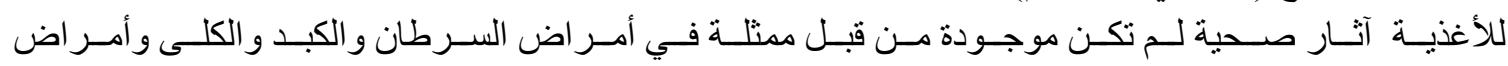
الحساسية و الجهاز العصبي وغير ها (جابر، ـ 99 (م).

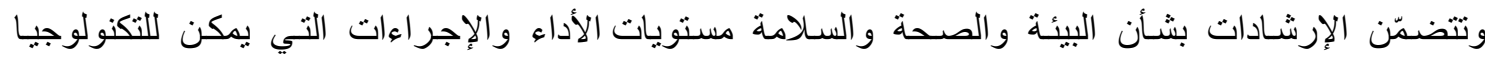
الحالية أن تحققها في المنشآت الجديدة بتكلفة معقو لثة.

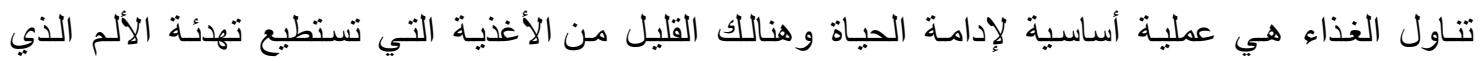

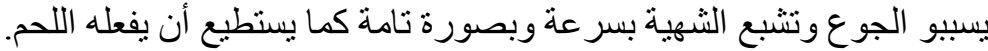

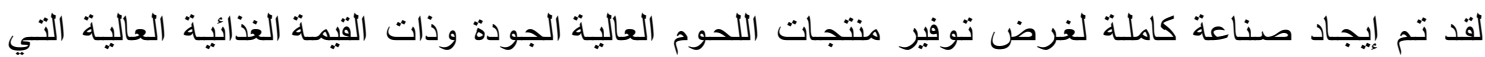

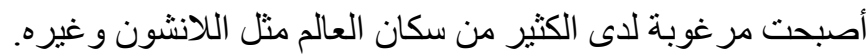

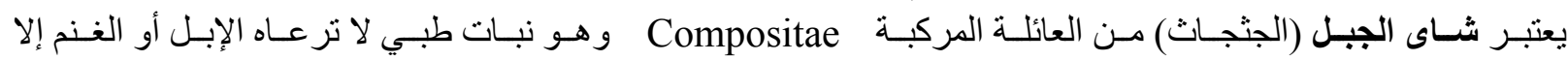

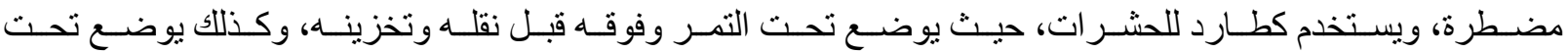

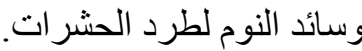

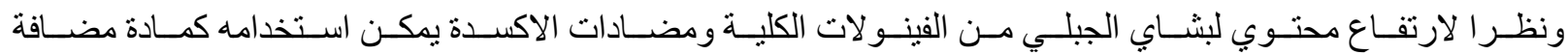

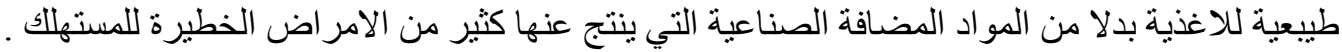

مشكلة الاراسة

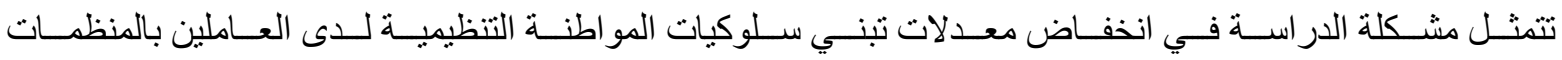

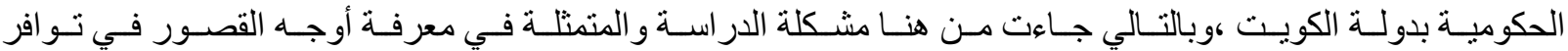

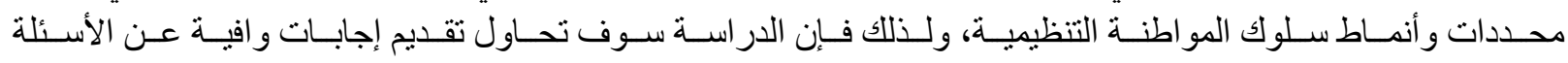
التالية:

ما هو مفهوم وأبعاد ومحددات ومقومات المو اطنة التنظيمية؟

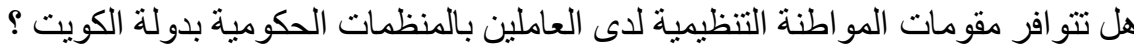

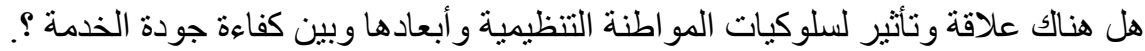

ا هداف الاراسة

1- - هناك بعض المواد الحافظة الكيميائية تؤثر على العمليات الحيوية للإنسان فتصيبة ببعض الأمر اض الخطيرة. r - حدوث التسمم الغذائي بسبب تتاول مو اد غذائية ملوثة بالسموم الميكروبية وغير ها.

r- فساد المو اد الغذائية وما ينتج عن تناولها من اضرار صحية بالغة واكتسابها صفات غير مرغوبة للإنسان ولا

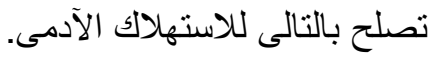

1 - در اسة تأثير الزيت العطرى لنبات شاى الجبل علي بعض أنواع الميكروبات المسبية لفساد الأغذية

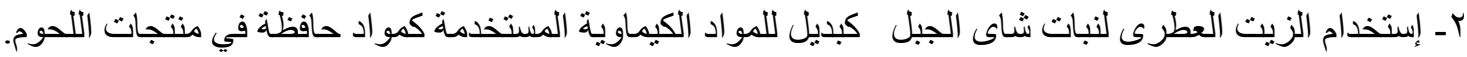


rـ يساعد على الزيت العطرى لنبات شاى الجبل خفض اعداد الميكروبات المرضية حيث انه مضاد للفطريا ت و البكتريا

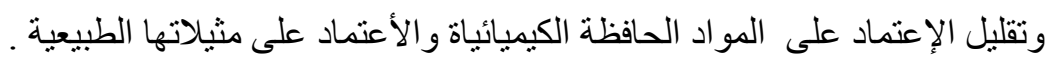

عـ يخفض الأعنماد على المو اد الحافظة المستوردة وذلك لتوفير العملة الصعبة

هـ يساعد إستخدام الزيت العطرى لنبات شاى الجبل على تقليل التلوث البيئى للمو اد الحافظة الكيميائية ويقلل من اضر ار ها.

\section{الطرق والأوات.}

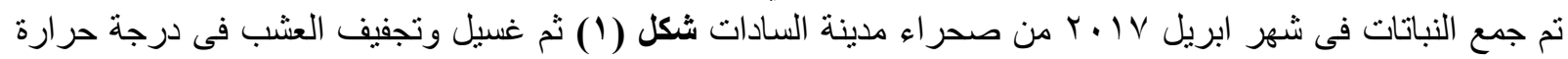

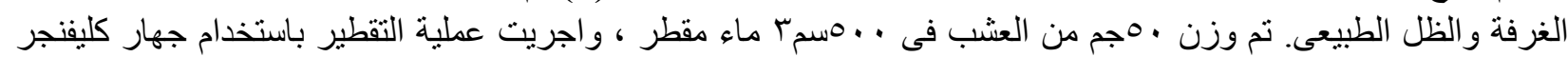

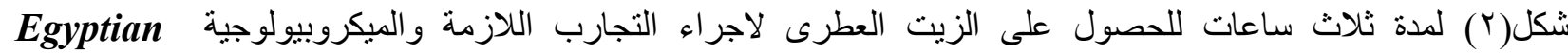

(Pharmacopoeia 1984)

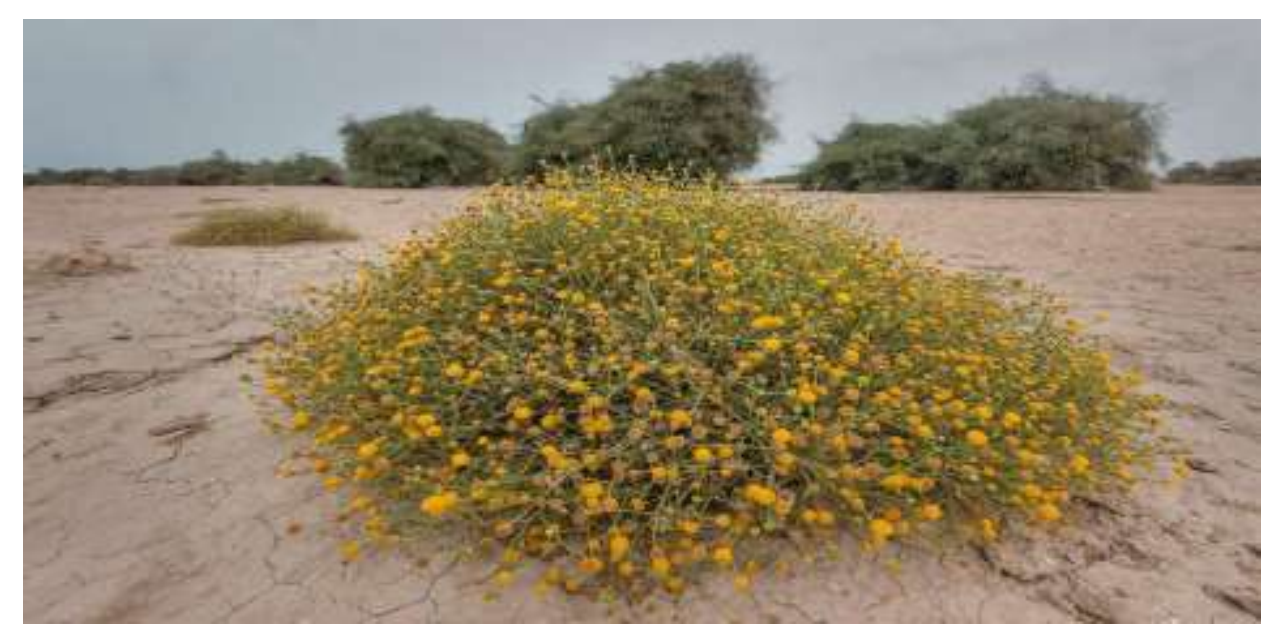

شكل (1) يوضح نموالثاى الجبلى طبيعيا فى منطقة صحر اء مدينة السادات

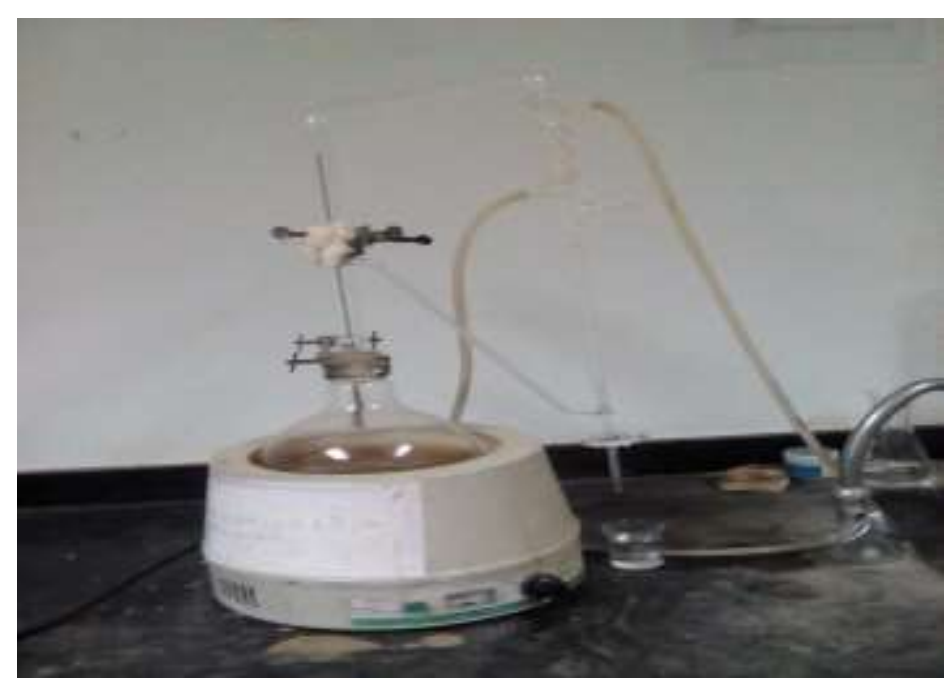

شكل (Y) جهاز التقطير بيخار الماء (كليفتجر) 


\section{بـ إختبار كفاءة زيت شاى الجبلي ضد الميكروبات Antimicrobial activity}

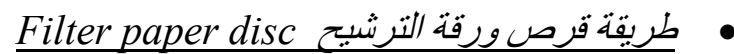

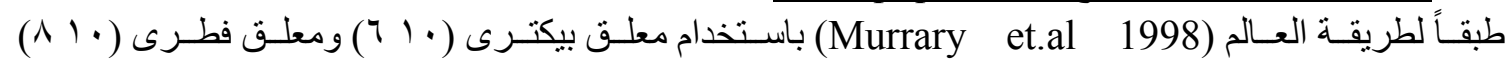

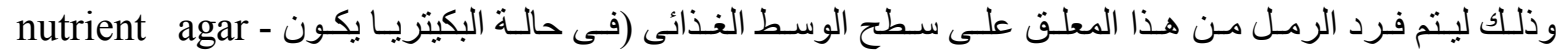

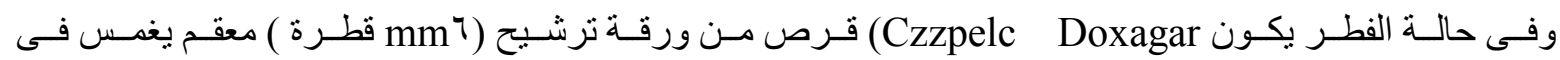
زيت شاى الجبلي وقرص أخر يغمس في ماء مقطر معقم (Control).

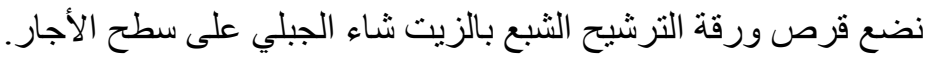

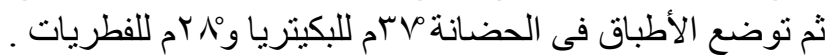

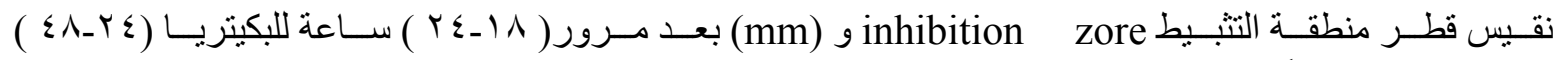
ساعة للفطريات طبقاً للعالم (Sardari et al 1998).

$$
\text { البكيتريا التىى تم اختبار ها هى :- }
$$

Erwinia Carotovora, Etnerobacter Cloacae, E.coli, Shigella, Bacillus Subtillis, Staphylococcus aureus and Staphylococcus epi

$$
\text { • • الفطريات التى تم اختبارها هي }
$$

Candida albicans, Aspergillus flavus, Fusarium oxysporum and Alternaria alternata

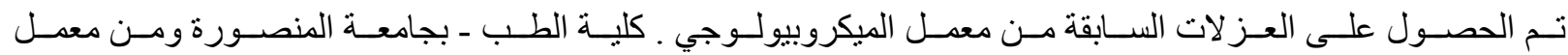
أمر اض النبات بمعهز الدر اسات و البحوث البيئية بجامعة مدينة السادات .

\section{عـ - اختبار النشاط ضد الأكسدة:}

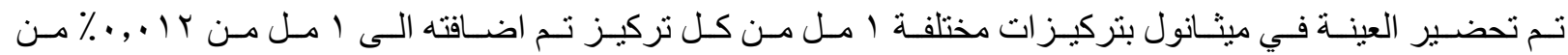
DPPH

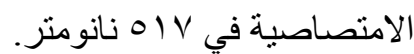

$$
\begin{aligned}
& \text { تم حساب النشاط الدضاد للأكسدة للعينة على النحو التالي: } \\
& \text { ](A1-A2)/A1] × } 100 \\
& \text { A1 } \\
& \text { A2 = عينة المستخلص الامتصاصية. A1 }
\end{aligned}
$$

تم حساب قيم IC50 باستخدام منحنى تتبيط حيث تم رسم ارتباط بين نسبة تثبيط DPPH وتركيز الات العينات

.(Ebrahimzadeh et al., 2009)

ع ـ مجموع محتوى البوليفينول من زيت شاى الجبل :

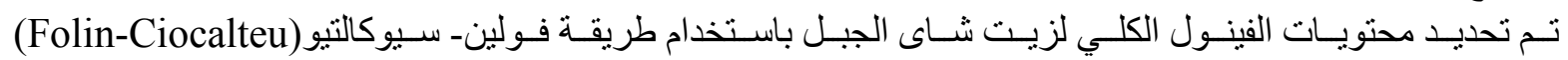

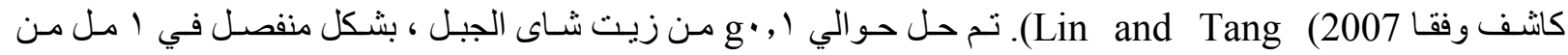

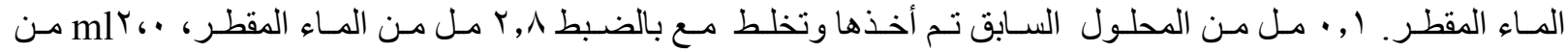

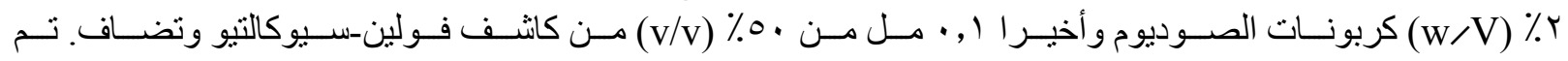

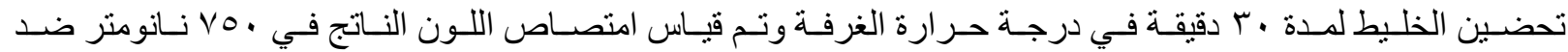

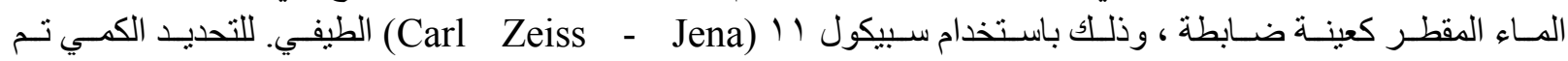




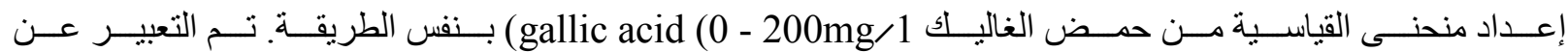
محتويات الفينول الكلية بمعادلة مليغر ام حمض الغاليك gallic acid (GAE)/g على أساس الوزن الجاف.

\section{النتائج والمناقشة}

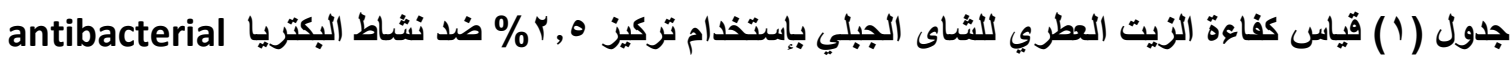
activity

\begin{tabular}{|c|c|c|}
\hline Organism & Sample & Streptomycin \\
\hline Erwinia Carotovora (G - ve) & $\begin{array}{l}12 \mathrm{~mm} \\
\text { cidal }\end{array}$ & $14 \mathrm{~mm}$ \\
\hline Etnerobacter Cloacae (G - ve) & $\begin{array}{l}10.6 \mathrm{~mm} \\
\text { cidal }\end{array}$ & $\begin{array}{l}15 \mathrm{~mm} \\
\text { Static }\end{array}$ \\
\hline E.coli(G - ve) & $\begin{array}{l}13 \mathrm{~mm} \\
\text { cidal }\end{array}$ & $\begin{array}{l}9 \mathrm{~mm} \\
\text { Static }\end{array}$ \\
\hline Shigella(G - ve) & $\begin{array}{l}14 \mathrm{~mm} \\
\text { cidal }\end{array}$ & $0.0 \mathrm{~mm}$ \\
\hline $\begin{array}{l}\text { Bacillus subtillis } \\
\text { (G+ve) }\end{array}$ & $\begin{array}{l}\text { 7. } 5 \mathrm{~mm} \\
\text { cidal }\end{array}$ & $0.0 \mathrm{~mm}$ \\
\hline $\begin{array}{l}\text { Staphylococcus aureus } \\
(\mathrm{G}+\mathrm{ve})\end{array}$ & $\begin{array}{l}10 \mathrm{~mm} \\
\text { Static }\end{array}$ & $\begin{array}{l}9 \mathrm{~mm} \\
\text { Static }\end{array}$ \\
\hline $\begin{array}{l}\text { Staphylococcus epi } \\
\text { (G + ve) }\end{array}$ & $\begin{array}{l}7 \mathrm{~mm} \\
\text { Static }\end{array}$ & $\begin{array}{l}9 \mathrm{~mm} \\
\text { Static }\end{array}$ \\
\hline
\end{tabular}

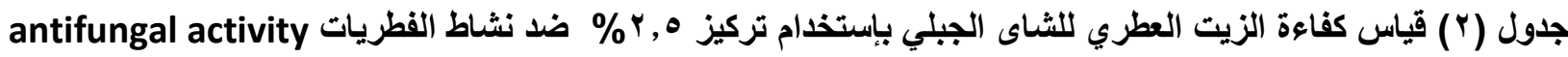

\begin{tabular}{|l|l|l|}
\hline Organism & Sample & Nystatin \\
\hline Candida albicans & $20 \mathrm{~mm}$ & $20.0 \mathrm{~mm}$ \\
\hline
\end{tabular}




\begin{tabular}{|l|l|l|}
\hline & cidal & \\
\hline Aspergillus flavus & $\begin{array}{l}30 \mathrm{~mm} \\
\text { cidal }\end{array}$ & $27.0 \mathrm{~mm}$ \\
\hline Fusarium oxysporum & $25 \mathrm{~mm}$ & $16.0 \mathrm{~mm}$ \\
\hline Alternaria alernata & cidal & \\
\hline & $25 \mathrm{~mm}$ & $16.0 \mathrm{~mm}$ \\
& cidal & \\
\hline
\end{tabular}

جدول (1) يوضح مدى كفاءة الزيت العطري من نبات الثاى الجبلي فى التأثير على نمو البكتيريا المختبرة وكان هذا التأثير:

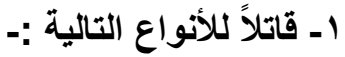

Erwinia Carotovora, Etnerobacter Cloacae, E.coli, Shigella and Bacillus Subtillis

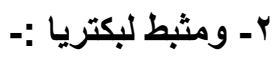

\section{Staphylococcus aureus and Staphylococcus ep}

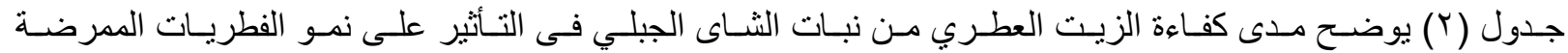

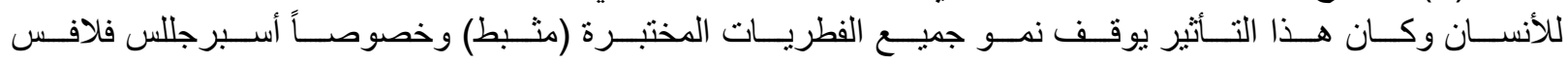

(Aspergillus flavus

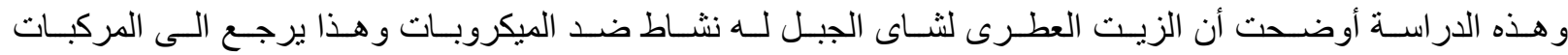

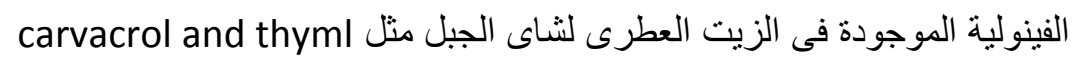

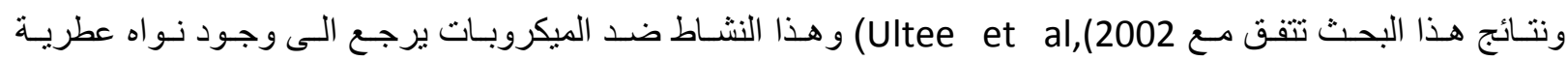

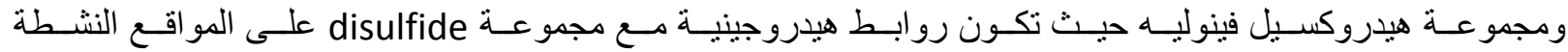
Ultee et al,(للإنزيم تؤدى الى عدم نشاط الإنزيم

\section{جدول رقم (ץ) المحتوى الكلى للقينولات والنشاط ضد الأكسده للزيت العطرى لشاى الجبل}

\begin{tabular}{|c|c|c|c|}
\hline $\mathrm{IC}_{50}(\mathrm{ug} / \mathrm{ml})$ & النشاط ضد الأكسده & $\begin{array}{l}\text { المحتوى الكلى للفينو لات } \\
\text { (mg GAE/g DW) }\end{array}$ & الأسم العلمى للعينـة \\
\hline 0.40 & 68.39 & 120 & Pulicaria undulata \\
\hline
\end{tabular}




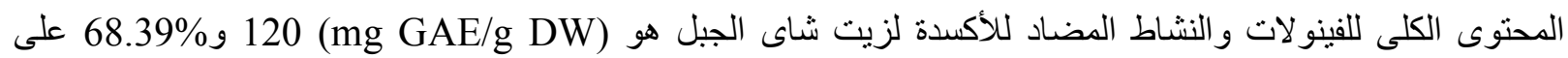

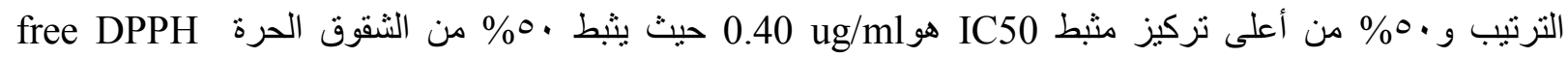
Radicals

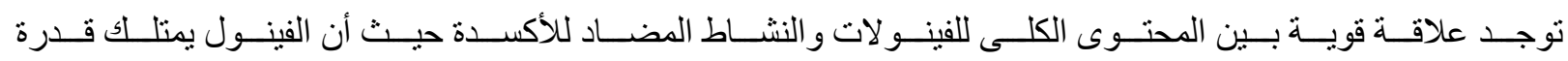
scavenging

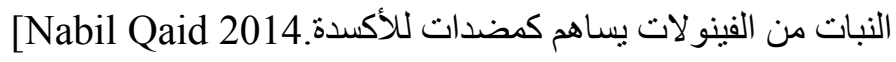

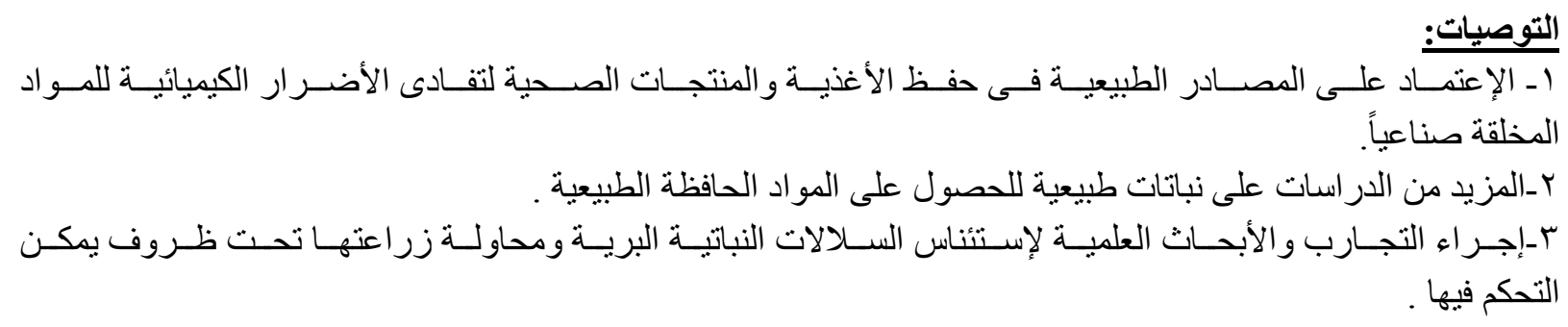

المراجع العربية :-

ا ـ البكيري، عبداله والدنشاري ، عز الدين وأبو لبن ، فاطهة (ـ 99 (م)، الغذاء وصحة المجتمع، مكتب التربية

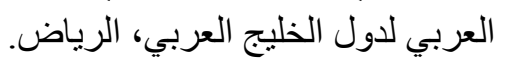

ץ.الثيخلي، جودت محمود (911 (م)، التسمم الغذائي، الهيئة العربية السعودية للمو اصفات و المقاييس، الرياض.

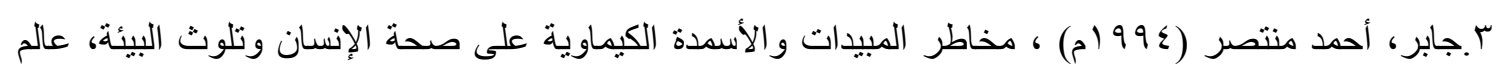

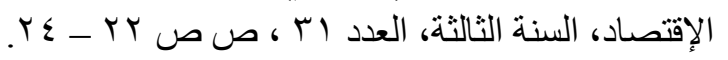

\section{المراجع الأجنبية:}

Ebrahimzadeh MA, Nabavi SM, Nabavi SF, Eslami B(2008): Free radical scavenging ability of menthnolic extract of Hyoscyamus squarrosus leaves. Pharmacologynline .2009; 2: 796-802

Egyptian Pharmacopoeia (1984). Permanent Commission of the Egyptian Pharmacopoeia, Faculty of Pharmacy, Kasr El Ainy, Cairo Egyptian Pharmacopoeia General

. Organization for Government Printing III

Murray, R.; Rosenthal, S.; Kobayashi, S.; pfaller, A. (1998). Medicals Microbiology. .3rd ed. St. Louis: Mosby, p.161

.Sardari, A.; Gholamreza, M.;Daneshtalab, M. (1998). Phytopharmaceuticals

.Part 1: Antifungal Activity of Selected Iranian and Canadian Plants

.Pharm. Biol., 36:180-188

Ultee A, Bennik MHJ, Moezelaar R(2002). The phenolic hydroxyl group of carvacrol is essential for action against the food-borne pathogen Bacillus cereus. Applied and .Environmental Microbiology 2002; 68: 1561-1568 
Nabil Qaid M Al-Hajj(2014)1,2, Hong Xing Wang1*, Chaoyang Ma1, Zaixiang Lou1 Mohanad Bashari1 and Riyadh Thabit1 Antimicrobial and Antioxidant Activities of the Essential Oils of Some Aromatic Medicinal Plants (Pulicaria inuloides-Asteraceae and (Ocimum forskolei-Lamiaceae

Tropical Journal of Pharmaceutical Research August 2014; 13 (8): 1287-1293 Hostettman, k. ;potterat, O.and Wolfender, S.L. (1998). The potential of higher plants as .asource of newdrugs chimia, 52: 10-17

Hashem, M.and Alamri, S.(2010). Contamination of common spices in Saudi Arabia .markets with potential mycotoxin

.Producing fungi. Saudi Sournal of Biological Sciences, 17:167-175

Elgayyar, M;Draughom, F.A.; Golden, D.A.; Mount, S.R. (2001). Antimicrobial activity of essemtial oils from plants against selected pathogenic and saprophytic micro .orgamisms.S.Food protect.64: 10la - 1024

.(Kotzekidou,p. , Gammakids, P.and Boulamatsis,A. (2007

Antimicrobial activity of some plant extracts and essential oils against food borne pathogens in vitro and $6 \mathrm{~m}$ the fate of inoculated pathogens in chocolate LWT- Food science and Technology, $41(\mathrm{~J}): 119-127$ 